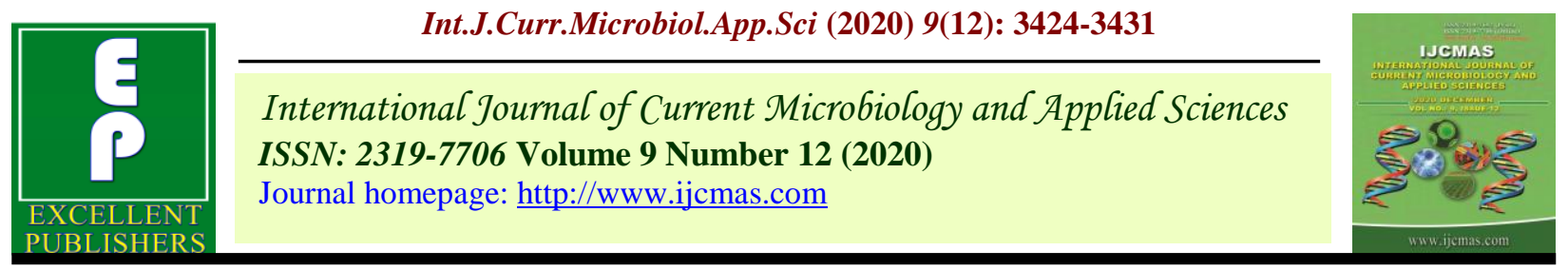

Original Research Article

https://doi.org/10.20546/ijcmas.2020.912.407

\title{
Effect of Site Specific Nutrient Management of White Yam on Soil Quality
}

\author{
J. A. Fathima ${ }^{1}$, R. Sreelekha ${ }^{1}$, R. Shiny ${ }^{2}$, S. S. Veena ${ }^{2}$ and G. Byju ${ }^{2 *}$ \\ ${ }^{1}$ National College, Manacaud, Thiruvananthapuram 695009, Kerala, India \\ ${ }^{2}$ ICAR-Central Tuber Crops Research Institute, Sreekariym P.O., \\ Thiruvananthapuram-695017, India \\ *Corresponding author
}

\section{A B S T R A C T}

\begin{tabular}{|l|}
\hline Key w ord s \\
Specific Nutrient \\
Management, \\
White yam \\
\hline Article Info \\
\hline Accepted: \\
28 November 2020 \\
Available Online: \\
10 December 2020 \\
\hline
\end{tabular}

White yam (Dioscorea rotundata Poir.) is an important tropical tuber crop which contributes to food and nutritional security for millions of people in many countries in Africa, South America and Asia. There exists large variability in the yield of white yam and one of the ways to bridge the gap is by managing the spatial and temporal variability in soil characteristics. The site specific nutrient management (SSNM) using QUEFTS model is very successful in increasing the yield, income and nutrient use efficiency. On station experiments were conducted to evaluate the performance of 8-year-old continuous SSNM on soil quality. Normalised SQI showed significant difference among the treatments which was significantly higher in SSNM treatment compared to present recommendation. The percentage of contribution of indicators to soil quality score showed that available iron is the major contributor followed by phosphatase activity and available phosphorus. The final normalized PCA based soil quality equation is Normalized SQI = $0.636($ Spnitrophenol/3) $+0.192(\mathrm{SFe} / 2)+0.173(\mathrm{SP} / 1)$.

\section{Introduction}

Sustainable agricultural intensification resulting in increased yield per unit area of land without compromising soil quality has been identified as the most promising approach towards food security. Yams (Dioscorea spp.) are one of the most important group of tropical food crops which are contributing to food and nutrition security of economically backward people in India, especially the Indian tribal population. Among the edible yam species, white yam (Dioscorea rotundata Poir.) is the most popular one globally.
Globally yams are cultivated in 60 countries, with 97 per cent of the production concentrated in Africa. The production of yams increased from 8.3 million tons in 1960 to 73 million tons in 2017 (FAOSTAT, 2017), which shows its ever increasing demand as food as well as in other applications. In India, yams that are cultivated in an area of about 27000 ha with a total production of 7.50 lakh tons and the average productivity yield is $28 \mathrm{t}$ $\mathrm{ha}^{-1}$ which is still far below it's the potential productivity of $80 \mathrm{t} \mathrm{ha}^{-1}$. The average productivity of yam ranges from $0.94 \mathrm{t} \mathrm{ha}^{-1}$ in Martinique to $30 \mathrm{t} \mathrm{ha}^{-1}$ in Ethiopia with a global average productivity of $8.35 \mathrm{t} \mathrm{ha}^{-1}$. This very clearly suggest that there is a 
possibility to increase yam production if we adopt site specific nutrient management (SSNM) which addresses the issue of spatial and temporal variability in soil properties.

Agronomic and physiological traits of this particular crop have the potential to produce harvestable yield under suboptimal conditions (Mukhopadhay et al., 2011). Under favourable conditions, yam can yield up to 60-75 $\mathrm{t} \mathrm{ha}^{-1}$ of fresh tuber in experimental fields (Lebot, 2006) and up to 30-40 $\mathrm{t} \mathrm{ha}^{-1}$ in commercial fields with improved cultivars and different nutrient management schedules. Because of its inherent tolerance to prolonged drought, altering soil $\mathrm{pH}$ and decreased soil nutrients (Rodriguez et al.,1982), yam production is seen to be expanding into marginal areas for subsistence. The differences between biological or potential yield and actual yields, known as yield gaps, are larger for yam in most of the growing countries. One of the plausible reasons for this large yield gap is the lack of management of spatial and temporal variability in soil and plant properties to bridge the yield gap.

In this context, more knowledge intensive, model based nutrient recommendations became inevitable in order to better accurately assess the wide yield gap. On station experiments were conducted to evaluate the performance of site specific nutrient management (SSNM) of different crops based on Quantitative Evaluation of Fertility of Tropical Soils (QUEFTS) model to estimate the soil plant balanced $\mathrm{N}, \mathrm{P}$ and $\mathrm{P}$ requirements in yams.

The modified QUEFTS model based recommendations also have been used for quantitative evaluation of yams in the recent past years which has been developed to predicted with potential and economic yields in different agro-ecologies for agro-advisory purposes (Byju et al., 2012; Kumar et al.,
2016; Ezui et al., 2018; Jinimol and Byju, 2018; Adiele., Shehu et al., 2019).

Results of SSNM studies in different crops show their superiority in increasing yield, income and nutrient use efficiency. Now there is a need to study its effect on soil quality based on the concept developed by different workers (Karlen et al., 2003; Letey et al., 2003). Hence the present study was aimed at understanding the effect of continuous site specific nutrient management (SSNM) of white yam on soil quality.

\section{Materials and Methods}

\section{Field experiment}

The study was conducted at ICAR-Central Tuber Crops Research Institute (ICARCTCRI), Sreekariyam, Thiruvananthapuram, Kerala during 2019-20. The SSNM experimental field which was subjected to the continuous fertilizer treatments for the past 8 years since 2012 was used for the present study. The six treatments and 4 replications per treatment were laid out in a randomized completed block design (RCBD).

The treatments include a nitrogen omission plot $(0 \mathrm{~N})$, phosphorus omission plot (OP), potassium omission plot $(0 \mathrm{~K})$, nitrogen, phosphorus and potassium omission plot (ONPK), site specific nutrient management (SSNM plot) and present recommendation (PR) plot. Plot size was $4.5 \mathrm{~m} \times 4.5 \mathrm{~m}$ and the sets were planted on mounds at a spacing of $0.9 x 0.9 \mathrm{~cm}$. The white yam variety, Sree Priya, a high yielding variety which was released from ICAR-CTCRI was used for the experiment. All other soil and crop management practices were followed uniformly as per Nair et al., (2004). Table 1 gives a detailed description of the different treatments used for the study. 


\section{Soil physico-chemical properties}

The soil samples were analyzed for different physico-chemical, biochemical and microbiological properties following standard procedures. Bulk density was determined by using Keen Raczkowskii box method (Wright, 1939). Soil $\mathrm{pH}$ was measured using 1:2.5 soil: water suspension using $\mathrm{pH}$ meter (Page et al., 1982). Organic carbon was determined by dichromate oxidation method (Walkley and Black, 1934). Labile carbon was determined by permanganate method (Weil et al., 2003). In this method slightly alkaline $\mathrm{KMnO}_{4}$ reacts with the most readily oxidizable (active) forms of soil carbon, converting $\mathrm{Mn}$ (VII) to $\mathrm{Mn}$ (II) and proportionally lowering absorbance of 550 $\mathrm{nm}$ light. Available N, P and $\mathrm{K}$ were estimated based on the procedures outlined by (Byju et al., 2010). The soil Exchangeable Ca and $\mathrm{Mg}$ present in the soil were extracted with neutral 1N ammonium acetate (Page et al., 1982) and the concentrations were determined using Perkin Elmer PinAAcle $900 \mathrm{H}$ model atomic absorption spectrometer. Then the $0.1 \mathrm{~N} \mathrm{HCl}$ were used to extract with available micronutrients like $\mathrm{Fe}, \mathrm{Mn}, \mathrm{Zn}, \mathrm{Cu}$ for soil below the $\mathrm{pH}$ of 6.5 (Lindsay, 1995).

\section{Soil biochemical properties}

The soil enzyme Urease (urea amino hydrolase) which catalyzes the hydrolysis of urea to $\mathrm{CO}_{2}$ and $\mathrm{NH}_{3}$. The colorimetric determinations were used for the estimation of the urea hydrolysis in soils after incubation for $24 \mathrm{hrs}$ at $30^{\circ} \mathrm{C}$ of soil with the urea solution (Gosewinkel and Broadbent, 1984). The amount of urea hydrolysed $\left(\mathrm{g}^{-1}\right.$ of the soil $\left.\mathrm{h}^{-1}\right)$ were estimated from the difference between the initial amount of urea added and that recovered after incubation. TTC assay in soil was estimated by using the method of Casida et al., (1964). The method based on extraction with ethanol and colorimetric determination of the TPF produced from the reduction of TTC in soils. Phosphatase activity was determined by using the method of Tabatabi and Bremner (1969). This method based on the release of p-nitrophenol released by phosphatase activity when the soil is incubated with buffer sodium p- nitrophenyl phosphate, sodium and toluene. The alkaline solution of p-nitrophenol is yellow in colour. The $\mathrm{CaCl}_{2}-\mathrm{NaOH}$ treatment serves to stop phosphatase activity. To develop the yellow colour used to estimate the phosphatase activity and to give the quantitative recovery of p-nitrophenol from the soil.

\section{Soil microbial properties}

Isolation of microorganisms from soil sample by using pour plate technique it is done by diluting comparatively large concentration of bacteria and fungi to a smaller concentration. Then $1 \mathrm{ml}$ of the serially diluted sample from $10^{-4}$ to the sterile petri plate containing Rose Bengal Agar (RBA) along with a pinch of antibiotics and $10^{-6}$ dilution is added to the petri plate containing nutrient agar is added kept for incubation. After $48 \mathrm{hrs}$ the colonies formed in nutrient agar (bacteria) and later $3^{\text {rd }}$ $-4^{\text {th }}$ day the colonies formed in RBA (fungi) were counted.

\section{Soil quality index}

Data were processed using SAS statistics programme (XLSTAT, trail version). Eighteen soil parameters were measured and the data were first checked for normality and then subjected to univariate analysis of variance (ANOVA). Variables with $\mathrm{F}$ statistically significant at $p<0.05$ were further analyzed by Principal Component analysis (PCA). The PCA is a mathematical procedure that gives a small number of uncorrelated variables or principal components (PC) from several correlated and thus it can reduce the size of the parameter 
data set. The first PC accounts for most of the remaining variability. It is assumed that PC 1 receiving high eigen values best representation of the system therefore only the PCs with eigen values more than one and those that explain at least 30 percent of the variations in data were included. Under a particular PC each soil property was given a weight or factor loading that represent the contribution of the variable to the composition of the PC. Within each PC, only highly weighted factors were retained for Minimum Data Set (MDS). Highly weighted factor loadings were defined as those having absolute values within 10 percent of highest factor loading. After determining the MDS indicators, they were grouped into three groups to determine the shape of the decision function.

The shape of the decision function was determined by expert knowledge and literature values quantifying the relationships between indicators and soil functioning. An upper asymptote or 'more is better' functions are considered (Soil Survey Staff. 1988). Once transformed, the indicators were weighted by the PCA results. Each PC explained a certain amount (percent) of the variation in the total data set. This percentage divided by the total percentage of variation explained by all PCs with eigenvectors higher than one, provided weighting factor for variables chosen under a given PC. The weighted MDS variable scores were then summed for each observation in the following formula,

$\mathrm{SQI}=\sum \mathrm{Wi} \times \mathrm{Si}$

Where $\mathrm{W}$ is the $\mathrm{PC}$ weighting factor and $\mathrm{S}$ is the indicator score. The calculated SQI treatment means were compared using ANOVA. It is assumed that higher index scores meant better soil quality or greater performance of soil function.

\section{Results and Discussion}

\section{Correlation matrix of soil physico-chemical and biological properties}

Results of correlation studies of soil physicochemical and biological properties at harvest are shown in Table 2. The OC content showed significantly positive correlation with $\mathrm{LC}(\mathrm{r}=$ $0.704), \mathrm{Mg}(\mathrm{r}=0.441)$, and $\mathrm{Ca}(\mathrm{r}=0.410)$. The available $\mathrm{N}$ shows significantly positive correlation with LC $(r=0.350)$ The $\mathrm{K}$ shows significantly positive correlation with $\mathrm{Ca}(\mathrm{r}=$ $0.585)$ and dehydrogenase $(r=0.50)$.

Table.1 Description of different treatments used for the study

\begin{tabular}{|l|c|c|c|}
\hline Treatment & $\mathbf{N}$ & $\mathbf{P}_{\mathbf{2}} \mathbf{O}_{\mathbf{5}}$ & $\mathbf{K}_{\mathbf{2}} \mathbf{O}$ \\
\hline ON-Nitrogen omission plot & 0 & 90 & 150 \\
\hline 0P-Phosphorus omission plot & 150 & 0 & 150 \\
\hline 0K-Potassium omission plot & 150 & 90 & 0 \\
\hline 0NPK-NPK omission plot & 0 & 0 & 80 \\
\hline Present recommendation (PR) plot & 80 & 60 & 0 \\
\hline $\begin{array}{l}\text { Site specific nutrient management } \\
\text { (SSNM) plot }\end{array}$ & $\begin{array}{l}\text { Secondary (Ca, Mg) and micronutrient (Fe, Mn, Zn, } \\
\text { Cu) - inclusive customised fertilizer formulation } \\
\text { developed for agro ecological unit (AEU) 8 of } \\
\text { Kerala state }\end{array}$ \\
\hline
\end{tabular}


Table.2 Correlation matrix of soil physico-chemical and biological properties at harvest

\begin{tabular}{|c|c|c|c|c|c|c|c|c|c|c|c|c|c|c|c|c|}
\hline Parameter & pH & OC & $\mathbf{N}$ & $\mathbf{P}$ & $\mathbf{K}$ & $\mathrm{Ca}$ & Mg & $\mathrm{Fe}$ & Mn & $\mathbf{Z n}$ & $\mathrm{Cu}$ & LC & Urease & $\begin{array}{l}\text { Dehydro } \\
\text { genase }\end{array}$ & Phosphatase & $\begin{array}{c}\text { Bulk } \\
\text { density }\end{array}$ \\
\hline pH & 1 & & & & & & & & & & & & & & & \\
\hline OC & 0.07 & 1 & & & & & & & & & & & & & & \\
\hline $\mathbf{N}$ & -0.24 & -0.04 & 1 & & & & & & & & & & & & & \\
\hline $\mathbf{P}$ & -0.02 & 0.16 & 0.07 & 1 & & & & & & & & & & & & \\
\hline $\mathbf{K}$ & -0.06 & $* 0.40$ & 0.18 & 0.06 & 1 & & & & & & & & & & & \\
\hline $\mathbf{C a}$ & -0.02 & $* 0.41$ & 0.21 & 0.00 & 0.59 & 1 & & & & & & & & & & \\
\hline Mg & 0.07 & $* 0.44$ & 0.24 & 0.21 & $* 0.43$ & $* 0.89$ & 1 & & & & & & & & & \\
\hline $\mathrm{Fe}$ & -0.27 & 0.11 & -0.13 & 0.06 & $* 0.48$ & 0.36 & 0.30 & 1 & & & & & & & & \\
\hline Mn & 0.21 & 0.11 & -0.19 & -0.21 & 0.39 & 0.21 & 0.08 & 0.35 & 1 & & & & & & & \\
\hline $\mathbf{Z n}$ & 0.08 & 0.18 & 0.26 & 0.24 & $* 0.44$ & 0.31 & $* 0.46$ & 0.21 & -0.01 & 1 & & & & & & \\
\hline $\mathrm{Cu}$ & -0.01 & 0.27 & 0.31 & 0.26 & 0.00 & 0.00 & 0.16 & -0.16 & -0.13 & 0.06 & 1 & & & & & \\
\hline LC & 0.09 & 0.70 & 0.35 & 0.23 & $* 0.52$ & 0.64 & $* 0.63$ & 0.12 & 0.09 & $* 0.38$ & 0.21 & 1 & & & & \\
\hline Urease & -0.29 & -0.30 & -0.25 & -0.26 & -0.32 & -0.40 & $*-0.50$ & -0.14 & 0.20 & $*_{-} 0.51$ & 0.00 & $*-0.56$ & 1 & & & \\
\hline Dehydrogenase & 0.18 & 0.30 & 0.23 & -0.08 & $* 0.50$ & $* 0.65$ & $* 0.62$ & 0.07 & 0.10 & $* 0.46$ & 0.17 & $* 0.59$ & -0.25 & 1 & & \\
\hline Phosphatase & 0.17 & -0.49 & -0.06 & 0.25 & -0.23 & -0.08 & -0.05 & -0.11 & -0.20 & 0.23 & -0.02 & -0.15 & -0.20 & 0.07 & 1 & \\
\hline Bulk density & 0.09 & -0.24 & 0.06 & -0.12 & -0.07 & -0.19 & -0.28 & -0.25 & 0.16 & -0.15 & -0.13 & -0.22 & -0.13 & -0.32 & 0.18 & 1 \\
\hline
\end{tabular}

Table.3 Results of principal component analysis of soil quality indicators for the first three PCs selected for computing SQI

\begin{tabular}{|l|l|c|c|}
\hline Principal components & PC1 & PC2 & PC3 \\
\hline Eigen value & 1.26 & 1.05 & 0.70 \\
\hline Loading factor & 0.55 & 0.46 & \\
\hline Percent & 41.82 & 34.88 & 23.31 \\
\hline Cumulative Percent & 41.82 & 76.70 & 100.00 \\
\hline Eigen vectors & & & \\
\hline Fe & -0.16 & 0.91 & 0.39 \\
\hline $\mathbf{P}$ & 0.67 & 0.39 & -0.63 \\
\hline p-Nitrophenol & 0.73 & -0.16 & 0.67 \\
\hline
\end{tabular}


Table.4 Normalized cumulative soil quality indices for different treatments

\begin{tabular}{|l|c|}
\hline Treatment & Normalized SQI \\
\hline N omission & 0.45 \\
\hline P omission & 0.56 \\
\hline K omission & 0.48 \\
\hline NPK omission & 0.55 \\
\hline PR & 0.46 \\
\hline SSNM & 0.56 \\
\hline LSD & 0.05 \\
\hline
\end{tabular}

Table.5 Effect of soil treatment on soil microbial count

\begin{tabular}{|l|c|c|}
\hline Treatment & $\begin{array}{c}\text { Bacterial count } \\
\left(\mathbf{1 0}^{-\mathbf{7}}\right)\end{array}$ & $\begin{array}{c}\text { Fungal count } \\
\left(\mathbf{1 0}^{-4}\right)\end{array}$ \\
\hline N omission & 1.5 & $\mathbf{1 1}$ \\
\hline P omission & 3.5 & $\mathbf{8 . 5}$ \\
\hline K omission & 4.0 & $\mathbf{7 . 5}$ \\
\hline NPK omission & 4.5 & $\mathbf{9 . 5}$ \\
\hline PR & 4.5 & $\mathbf{7 . 5}$ \\
\hline SSNM & $\mathbf{3 . 5}$ & $\mathbf{8 . 0}$ \\
\hline
\end{tabular}

Fig.1 Effect of different fertilizer treatments on soil quality index (SQI)

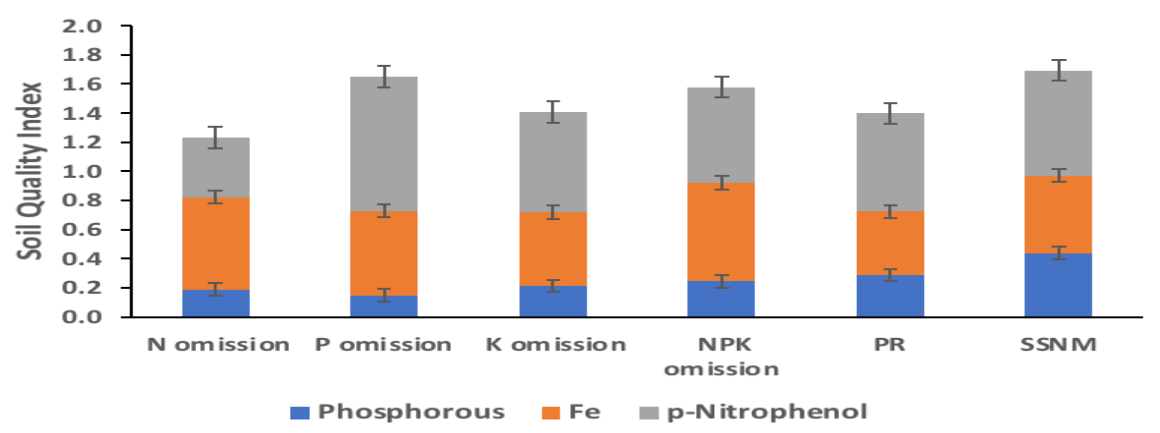

Fig.2 Percentage contribution of indicators to soil quality

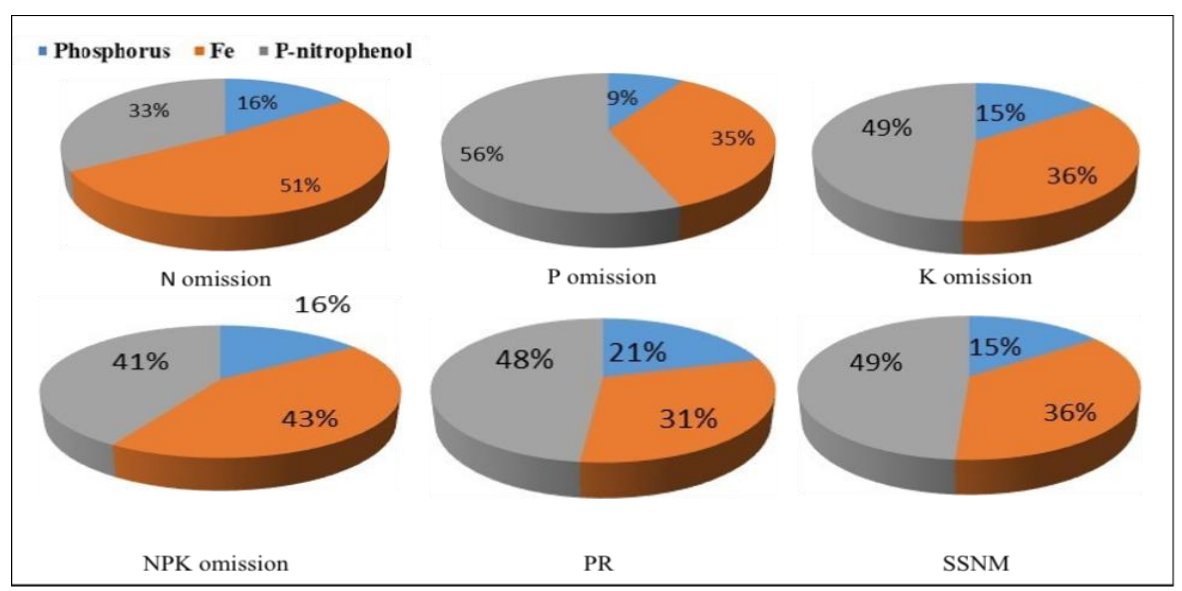


The $\mathrm{Ca}$ shows significantly positive correlation with $\mathrm{Mg}(\mathrm{r}=0.892)$ and dehydrogenase. $\mathrm{Mg}$ showed significant correlation with $\mathrm{Zn}(\mathrm{r}=0.46), \mathrm{LC}(\mathrm{r}=0.63)$ and dehydrogenase $\quad(\mathrm{r}=0.62)$.and negative correlated to LC showed significantly positive correlation with urease $(\mathrm{r}=-0.50)$. Zn showed significant positive correlation with LC (0.38) and dehydrogenase $(\mathrm{r}=0.46)$ and significant negative correlation with urease $(\mathrm{r}=0.51)$. Labile carbon showed significant positive correlation with dehydrogenase $(\mathrm{r}=0.59)$ and negative correlation with urea $(\mathrm{r}=-0.56)$.

\section{Soil quality}

\section{Principal component analysis}

The effect of different treatments on soil quality was evaluated by computing soil quality index (SQI). The soil parameters which showed significant difference among the treatments were selected for principal component analysis (PCA). Considering the previously mentioned soil characteristics three PCs were generated using the principal component analysis (Table 3).

Eigen values highlighted in bold corresponds to the PCs examined for the index, bold. Based on Kasier (1960) criterion, the number of data set to retain was up to PC3, as the eigen value started to be lower than 0.5 from PC1 onwards. These three PCs explained $100 \%$ of the total variance. The PC1, PC2 and PC3 explained $41.8,34.88$ and $23.31 \%$ of the total respectively. In $\mathrm{PC} 1$, pnitrophenol showed high value which is more than that of other Eigen vectors and so it was considered. Thus in PC2 Fe showed highest value and so it was considered. In PC3 pnitrophenol showed very highly weighed variable but was not considered as it was already considered in PC1. Among the rest of the eigen values, phosphorus showed highest value and was considered.

\section{Soil quality index (SQI)}

The final normalized PCA based soil quality equation is:

Normalized SQI $=0.636($ Spnitrophenol/3) + $0.192(\mathrm{SFe} / 2)+0.173(\mathrm{SP} / 1)$

Figure 1 and Table 4 show the values of normalized cumulative soil quality indices for weighted MDS variable scores for the various treatments. A higher soil quality index was observed for, SSNM (0.56) and followed by $\mathrm{P}$, NPK omission and lowest value was showed by $\mathrm{N}$ omission (0.45) followed by $\mathrm{K}$ omission and PR treatment.

Percentage of contribution of indicators to soil quality score by each parameters is shown in figure 1. In $\mathrm{N}$ omission treatment highest percentage of contribution of soil quality index was shown by $\mathrm{Fe}(51 \%)$ and lowest by phosphorous (16\%). In $\mathrm{P}$ omission treatment the highest percentage of contribution to soil quality index was shown by pnitrophenol (56\%) and lowest by phosphorous (9\%). In K omission treatment highest percentage of contribution of soil quality index was shown by pnitrophenol (49\%) and lowest by phosphorous (15\%). In NPK omission treatment highest percentage of contribution of soil quality index was shown by Fe (43\%) and lowest by phosphorus (16\%). In PR omission treatment highest percentage of contribution of soil quality index was shown by pnitrophenol (48\%) and lowest by phosphorous (21\%). In SSNM omission treatment highest percentage of contribution of soil quality index was shown by pNitrophenol (49\%) and lowest by phosphorous (15\%).

\section{Soil microbial properties}

Table 5 shows the effect of soil treatment on microbial count in the soil sample. Highest 
number of bacterial colonies were found in NPK omission and PR treatments $(4.5 \times 10-7)$ and least number in $\mathrm{N}$ omission treatment (1.5 $\mathrm{x} 10-7)$. Fungal count was found to be higher in $\mathrm{N}$ omission treatment (11x10-4) and lowest number in in $\mathrm{K}$ omission and PR treatments (7.5 x10-4).

\section{References}

Andrews, S.S., D.L. Karlen, and C.A. Cambardella. 2004. The soil management assessment framework: A quantitative soil quality evaluation method. Soil Sci. Soc. Am. J. 68:1945-1962.

Bray RH, Kurtz LT (1945) Determination of total, organic and available forms of phosphorus in soils. Agron J 59: 39-45.

Byju G., Nedunchezhiyan M, Ravindran C S, Mithra S et al., 2012. Modeling the response of cassava to fertilizers: A site specific nutrient management approach for higher tuberous root yield. Commun Soil Sci Plant Anal 43: 1149-62.

Casida, L.; Klein, D. and Santoro, T. (1964). Soil Dehydrogenase Activity. Soil Science, 98, pp. 371-376.

FAO. 2013. Save and grow: cassava. A guide to to sustainable production intensification. FAO, Rome, Italy.

Karlen, D.L., J.W. Doran, B.J. Weinhold, and S.S. Andrews. 2003. Soil quality: Humankind's foundation for survival. J. Soil Water Conserv. 58:171-179.

Page, A.L, R.H. Milller, and D.R. Keeney. 1982. Methods of soil analysis Part 2. Chemical and microbiological properties. Agronomy series, No.9, ASA, SSSA,
Madison, Wisconsin, USA.

Remya Remesh K.R., G. Byju, Sabitha Soman, Saravanan Raju and V. Ravi. 2019. Projected changes in mean temperature and total precipitation and climate suitability of yam (Dioscorea spp.) in major growing environments of India. Current Horticulture, Jan-July 2019.

Sen, K., and R. Mukhopadhay. "LM and SEM studies on stomatal morphotypes, epidermal characteristics and spore morphology of some indian species of Cheilanthes sw." Bioresearch Bulletin 5 (2011): 304-310.

Soil Survey Staff. 1988. A rapidly executable point protocol for partial soil quality evaluation. USDA - NRCS National Soil Survey Centre, Lincoln, NE, USA.

Tabatabai, M. A., and J. M. Bremner. "Use of pnitrophenyl phosphate for assay of soil phosphatase activity." Soil biology and biochemistry 1.4 (1969): 301-307.

Van Bruggen, Ariena HC, and Alexander M. Semenov. "In search of biological indicators for soil health and disease suppression." Applied Soil Ecology 15.1 (2000): 13-24.

Walkley, A., and I.A. Black. 1934. An examination of the degtjareff method for determining soil organic matter and a proposed modification of the chromic acid titration method. Soil Sci. 37:29-38.

Weil, R.R., K.R. Islam, M.A. Stine, J.B. Gruver, and S.E.S. Liebig. 2003. Estimating active carbon for soil quality assessment: a simplified method for laboratory and field use. Am. J. Altern. Agric. 18(1): 3-17.

\section{How to cite this article:}

Fathima, J. A., R. Sreelekha, R. Shiny, S. S. Veena and Byju, G. 2020. Effect of Site Specific Nutrient Management of White Yam on Soil Quality. Int.J.Curr.Microbiol.App.Sci. 9(12): 3424-3431. doi: https://doi.org/10.20546/ijcmas.2020.912.407 